Herta Flor • Thomas Elbert • Werner Mühlnickel

Christo Pantev $\cdot$ Christian Wienbruch $\cdot$ Edward Taub

\title{
Cortical reorganization and phantom phenomena in congenital and traumatic upper-extremity amputees
}

\begin{abstract}
The relationship between phantom limb phenomena and cortical reorganization was examined in five subjects with congenital absence of an upper limb and nine traumatic amputees. Neuromagnetic source imaging revealed minimal reorganization of primary somatosensory cortex in the congenital amputees $(M=0.69 \mathrm{~cm}, \mathrm{SD}$ 0.24 ) and the traumatic amputees without phantom limb pain $(M=0.27 \mathrm{~cm}, \mathrm{SD} 0.25)$; the amputees with phantom limb pain showed massive cortical reorganization $(M=2.22 \mathrm{~cm}, \mathrm{SD} 0.78)$. Phantom limb pain and nonpainful phantom limb phenomena were absent in the congenital amputees. Whereas phantom limb pain was positively related to cortical reorganization $(r=0.87)$, nonpainful phantom phenomena were not significantly correlated with cortical reorganization $(r=0.34)$. Sensory discrimination was normal and mislocalization (referral of stimulation-induced sensation to a phantom limb) was absent in the congenital amputees. The role of peripheral and central factors in the understanding of phantom limb pain and phantom limb phenomena is discussed in view of these findings.
\end{abstract}

Key words Cortical plasticity · Phantom limb pain . Traumatic amputation - Congenital aplasia . Neuromagnetic source imaging · Human

H. Flor $(\bowtie) \cdot$ W. Mühlnickel

Department of Psychology, Clinical Psychology

and Behavioral Neuroscience, Humboldt-University,

Hausvogteiplatz 5-7, D-10117 Berlin, Germany

e-mail: hflor@rz.hu-berlin.de, Fax:+49-30-20377308

T. Elbert

Department of Psychology, University of Konstanz, Germany

C. Pantev $\cdot$ C. Wienbruch

Institute of Experimental Audiology, University of Münster,

Germany

E. Taub

Department of Psychology, University of Alabama at Birmingham, USA

\section{Introduction}

The occurrence of a phantom limb, i.e., the subjective feeling of the continued presence of a body part that is no longer present, seems to be an almost universal consequence of amputation. Phantom limbs develop in 80 $100 \%$ of traumatic amputations; in about $50-80 \%$ of those cases they are painful (Jensen et al. 1983; Sherman et al. 1984). Whereas there is general agreement that painful and nonpainful phantom limbs occur in traumatic amputees whose amputations took place in adult life, there is conflicting data concerning persons whose amputation is congenital or occurred in early childhood. Beginning with Pick (1915), it was assumed by a number of investigators that an image of the body develops only with experience; congenital or early traumatic amputees were thought not to have a well-developed body image and could therefore not experience phantom limbs. This conception was supported in a number of studies for both congenital and child amputees (Riese and Bruck 1950; Kolb 1954; Simmel 1956, 1961; Jørring 1971). In children, it appeared that the presence of phantom limbs became more likely the more advanced the age of the child was at the time of the amputation. Whereas children who were amputated before the age of 3 years virtually never reported phantom limbs, the number experiencing phantom limbs increased up to about the age of 8 years, when phantom limbs became as frequent as in adult amputees (Riese and Bruck 1950; Boeri and Negri 1954; Simmel 1956).

These early results were, however, challenged when Weinstein and his colleagues (Weinstein and Sersen 1961; Weinstein et al. 1964; Vetter and Weinstein 1967) and Poeck (1964) found that some congenital (up to $18 \%$ in Weinstein et al. 1964) and early child amputees did report phantom limbs. These studies were criticized for using the testimony of children who might be more prone to respond to demand characteristics of the situation than adults (Skoyles 1990). Several studies assessed congenital amputees when they were adult; these studies reported extremely low numbers of phantom limbs. For example, Burchard (1965) carefully examined and ques- 
tioned 17 adult subjects with congenital absence of limbs; only one of his subjects reported sensations similar to those of a phantom limb, although that subject reported "imagining" the phantom limb rather than actually "feeling" it. Sadaah and Melzack (1994) reported the occurrence of phantom limbs in 4 out of $65(7 \%)$ of the congenital amputees questioned in a mail survey. However, in all 4 cases, the experience of a phantom limb occurred only after subsequent trauma to the limb (e.g., surgery). Phantom limb pain seems to be virtually absent in congenital amputees (Simmel 1956; Jørring 1971). Only Sohn (1914) described a case of phantom limb pain in a congenital amputee. This amputee had, however, pain in the stump radiating down to the phantom fingers. Since this patient still had a very small rudimentary hand it is not clear if the hand just felt inflated (and painful) due to the severe stump pain or if there was true phantom limb pain. In addition, one of the patients of Weinstein et al. (1964) might have displayed a painful phantom limb (the subject described the phantom limb as "aching"), but no further information is given.

More recent data suggest that children and adolescents have a higher occurrence of phantom limbs and phantom pain than seems to have been estimated previously (cf., Krane and Heller 1995; Sherman 1997). For example, Krane and Heller (1995) report the occurrence of phantom limbs in $100 \%$ of the 24 children and adolescents they examined, and phantom limb pain in $92 \%$. They relied, however, on mail surveys, which may be inadequate to differentiate clearly between the symptoms of nonpainful phantom limbs, painful phantom limbs, nonpainful stump sensations, and stump pain. This possibility prompted us to use extensive, structured interviews (see also Burchard 1965).

The reasons for the report of varying percentages of nonpainful phantom limbs and phantom limb pain in congenital as compared to traumatic amputees have thus far not been sufficiently explored. One problem with some of the studies are the shortcomings related to the method of determining the presence or absence of phantom phenomena. In addition, both peripheral and central factors might be different for the two groups of subjects, giving rise in them to the experience of different types of phantom phenomena. Whereas traumatic (including child) amputees have clearly defined deafferentation involving the section of existing axons, congenital amputees are not actually "amputees." Rather their condition involves an aplasia of the limbs such as in phocomelia (a congenital deformity in which the limbs are extremely shortened) and peromelia (congenital malformation). The limb often has the appearance of having undergone an amputation (Holmes and Borden 1974; Herrman and Opitz 1977; Pfeiffer and Santelman 1977), but no nerves have been severed as in traumatic or surgical amputation. Instead, a lack of blood supply to the hand or malformation due to genetic or unknown causes may lead to the congenital absence of the limb or parts of it.

So far, brain processes related to congenital aplasias have rarely been studied, although they might elucidate some of the differences found between congenital and traumatic amputees. Hall et al. (1990) used transcranial magnetic stimulation to study possible reorganization of the motor cortex in two congenital amputees and two traumatic amputees and four healthy controls. They found that motor potentials on the amputated side could be evoked with a lower threshold and from a larger area in both congenital and one early traumatic amputee but not in a late traumatic amputee. Unfortunately, Hall et al. (1990) did not provide any further information on the patients they studied. In contrast, Cohen et al. (1991) reported that only the traumatic amputees showed enhanced reactivity in the musculature close to the amputation site, but this did not occur in a congenital amputee. The findings of Kew et al. (1994) are consistent with those of the latter experiment. Kew et al. studied three traumatic and three congenital amputees using positron emission tomography and transcranial magnetic stimulation during paced shoulder movements on the intact and the amputation side. They found much larger and much more widespread activation in the sensorimotor cortices contralateral to the side of the amputation in the traumatic amputees than in the congenital amputees, who showed only a slightly but nonsignificantly higher activation of the primary somatosensory and primary motor (SI/MI) areas. Higher corticospinal excitability contralateral to the missing limb was found only in the traumatic amputees. In addition, the deafferented SI/MI cortex of the traumatic amputees showed some response to ipsilateral arm movement; this activation was absent in the congenital amputees. An additional area of activation was found in Brodman's area 5 of the posterior parietal cortex in traumatic amputees; this was not present in the congenital amputees. Unfortunately, Kew et al. did not report on the presence of phantom limb pain in their traumatic amputees.

The purpose of this study was to carry out a detailed analysis of the organization of the SI by neuromagnetic source imaging and to determine its relationship with both painful and nonpainful phantom phenomena in congenital and traumatic amputees. In line with our previous results (Flor et al. 1995), we expected to find significant phantom limb pain and cortical reorganization in traumatic amputees, with a close association between the two, but no significant association of nonpainful phantom limb phenomena and cortical reorganization. In view of the fact that most previous work reported an absence of phantom limb pain in congenital amputees, we hypothesized that there would be little or no cortical reorganization in primary somatosensory cortex of these individuals. In addition, we sought to determine sensory perception and possible mislocalization (or referral of stimulation-induced sensation to a phantom limb) in the congenital amputees in an effort to elucidate potential additional perceptual correlates of cortical reorganizational changes. 
Table 1 Demographic, perceptual, and cortical reorganizational data for congenital and traumatic amputees

\begin{tabular}{|c|c|c|c|c|}
\hline \multirow[t]{2}{*}{ Variable } & & \multirow{2}{*}{$\begin{array}{l}\text { Congenital amputes } \\
(n=5)\end{array}$} & \multicolumn{2}{|l|}{ Traumatic amputes } \\
\hline & & & $\begin{array}{l}\text { Without phantom } \\
\text { limb pain }(n=5)\end{array}$ & $\begin{array}{l}\text { With phantom } \\
\text { limb pain }(n=4)\end{array}$ \\
\hline \multicolumn{5}{|l|}{ Demographic data } \\
\hline Age (years) & $\begin{array}{l}\text { Mean } \\
\text { SD }\end{array}$ & $\begin{array}{r}31.60 \\
9.76\end{array}$ & $\begin{array}{l}50.80 \\
19.24\end{array}$ & $\begin{array}{l}58.35 \\
18.82\end{array}$ \\
\hline Gender $(n)$ Male & & 1 & 4 & 4 \\
\hline Female & & 4 & 1 & 0 \\
\hline $\begin{array}{l}\text { Time since amputation } \\
\text { (years) }\end{array}$ & $\begin{array}{l}\text { Mean } \\
\text { SD }\end{array}$ & $\begin{array}{r}31.60 \\
9.76\end{array}$ & $\begin{array}{l}28.60 \\
28.62\end{array}$ & $\begin{array}{l}37.23 \\
24.17\end{array}$ \\
\hline Age at amputation (years) & $\begin{array}{l}\text { Mean } \\
\text { SD }\end{array}$ & Prenatal & $\begin{array}{l}22.80 \\
17.91\end{array}$ & $\begin{array}{r}21.80 \\
7.75\end{array}$ \\
\hline Trauma to arm $(n)$ & & 3 & 5 & 4 \\
\hline Stump length $(\mathrm{cm})$ & $\begin{array}{l}\text { Mean } \\
\text { SD }\end{array}$ & $\begin{array}{l}36.30 \\
14.52\end{array}$ & $\begin{array}{l}29.67 \\
15.70\end{array}$ & $\begin{array}{r}23.50 \\
8.69\end{array}$ \\
\hline \multicolumn{5}{|l|}{ Perceptual data } \\
\hline Stump sensation $(n)$ & $\begin{array}{l}\text { Mean } \\
\text { SD }\end{array}$ & $\begin{array}{l}0 \\
0\end{array}$ & $\begin{array}{l}0.80 \\
0.84\end{array}$ & $\begin{array}{l}2.50 \\
1.00\end{array}$ \\
\hline Phantom sensation $(n)$ & $\begin{array}{l}\text { Mean } \\
\text { SD }\end{array}$ & $\begin{array}{l}0 \\
0\end{array}$ & $\begin{array}{l}2.20 \\
2.05\end{array}$ & $\begin{array}{l}2.50 \\
2.65\end{array}$ \\
\hline Stump pain intensity VAS $(0-100)$ & $\begin{array}{l}\text { Mean } \\
\text { SD }\end{array}$ & $\begin{array}{r}6.00 \\
13.42\end{array}$ & $\begin{array}{r}9.60 \\
13.44\end{array}$ & $\begin{array}{l}41.00 \\
28.30\end{array}$ \\
\hline Phantom limb pain intensity (MPI value) & $\begin{array}{l}\text { Mean } \\
\text { SD }\end{array}$ & $\begin{array}{l}0 \\
0\end{array}$ & $\begin{array}{l}0 \\
0\end{array}$ & $\begin{array}{l}3.18 \\
1.06\end{array}$ \\
\hline \multicolumn{5}{|l|}{ Two-point discrimination ( $\mathrm{mm}$ ) } \\
\hline Stump & $\begin{array}{l}\text { Mean } \\
\text { SD }\end{array}$ & $\begin{array}{l}85.6 \\
60.2\end{array}$ & $\begin{array}{l}77.0 \\
52.4\end{array}$ & $\begin{array}{l}61.0 \\
53.5\end{array}$ \\
\hline Contralateral arm & $\begin{array}{l}\text { Mean } \\
\text { SD }\end{array}$ & $\begin{array}{l}75.2 \\
38.3\end{array}$ & $\begin{array}{l}72.8 \\
49.6\end{array}$ & $\begin{array}{l}75.2 \\
38.3\end{array}$ \\
\hline $\begin{array}{l}\text { Mislocalization }(n) \\
\text { Points yielding mislocalization }(n)\end{array}$ & $\begin{array}{l}\text { Mean } \\
\text { SD }\end{array}$ & $\begin{array}{l}0 \\
0 \\
0\end{array}$ & $\begin{array}{l}1 \\
0.40 \\
0.89\end{array}$ & $\begin{array}{l}3 \\
5.78 \\
5.32\end{array}$ \\
\hline Telescoping $(n)$ & & 0 & 2 & 4 \\
\hline \multicolumn{5}{|l|}{ Physiological data } \\
\hline $\begin{array}{l}\text { Cortical reorganization } \\
\text { Lip }(\mathrm{cm})\end{array}$ & $\begin{array}{l}\text { Mean } \\
\text { SD }\end{array}$ & $\begin{array}{l}0.69 \\
0.24\end{array}$ & $\begin{array}{l}0.27 \\
0.25\end{array}$ & $\begin{array}{l}2.22 \\
0.78\end{array}$ \\
\hline Toe $(\mathrm{cm})$ & $\begin{array}{l}\text { Mean } \\
\text { SD }\end{array}$ & $\begin{array}{l}0.72 \\
0.31\end{array}$ & $\begin{array}{l}- \\
-\end{array}$ & $\begin{array}{l}- \\
-\end{array}$ \\
\hline
\end{tabular}

\section{Materials and methods}

Subjects

Five congenital and nine traumatic amputees, five without and four with phantom limb pain, participated in the study, as well as ten healthy controls. The traumatic group comprised a subsample of a large sample of 100 unilateral upper-extremity amputees, chosen according to availability for the investigation in the neuromagnetometer laboratory. All amputees volunteered for the project in response to inquiry by their prosthetist or physician. Table 1 shows age, gender, and time since amputation of the study sample. The congenital amputees were younger than the traumatic amputees. Time since amputation was not significantly different between the groups. The mean age at the time of the amputation was 22 years in the traumatic amputees (ranging from 12 to 52 years). The subjects underwent a comprehensive neurological and psychological investigation, which included detailed assessments of phantom pain and phantom sensations, stump pain and stump sensations, preamputation pain, telescoping, and mislocalization (Flor et al. 1995; Knecht et al. 1996). The comparison sample of ten healthy controls was matched with the congenital amputees for age ( $M=36.07$ years, SD 12.05, range 23-51 years) and gender (six women, four men).

\section{Assessment of perceptual phenomena}

The presence of referral of stimulation-induced sensation to the phantom limb (mislocalization) was assessed by probing the surface of the entire body with a q-tip while the patient had to indicate the quality, location, and intensity of the primary sensation he or she experienced as well as the presence of any secondary (e.g., phantom) sensations (Ramachandran et al. 1992). No other modalities (e.g., pin prick) were probed. Sensory testing included two-point discrimination and electric and thermal perception, pain threshold, and pain tolerance. These were assessed only in the congenital amputees and the comparison group of healthy control subjects. Two-point dis- 


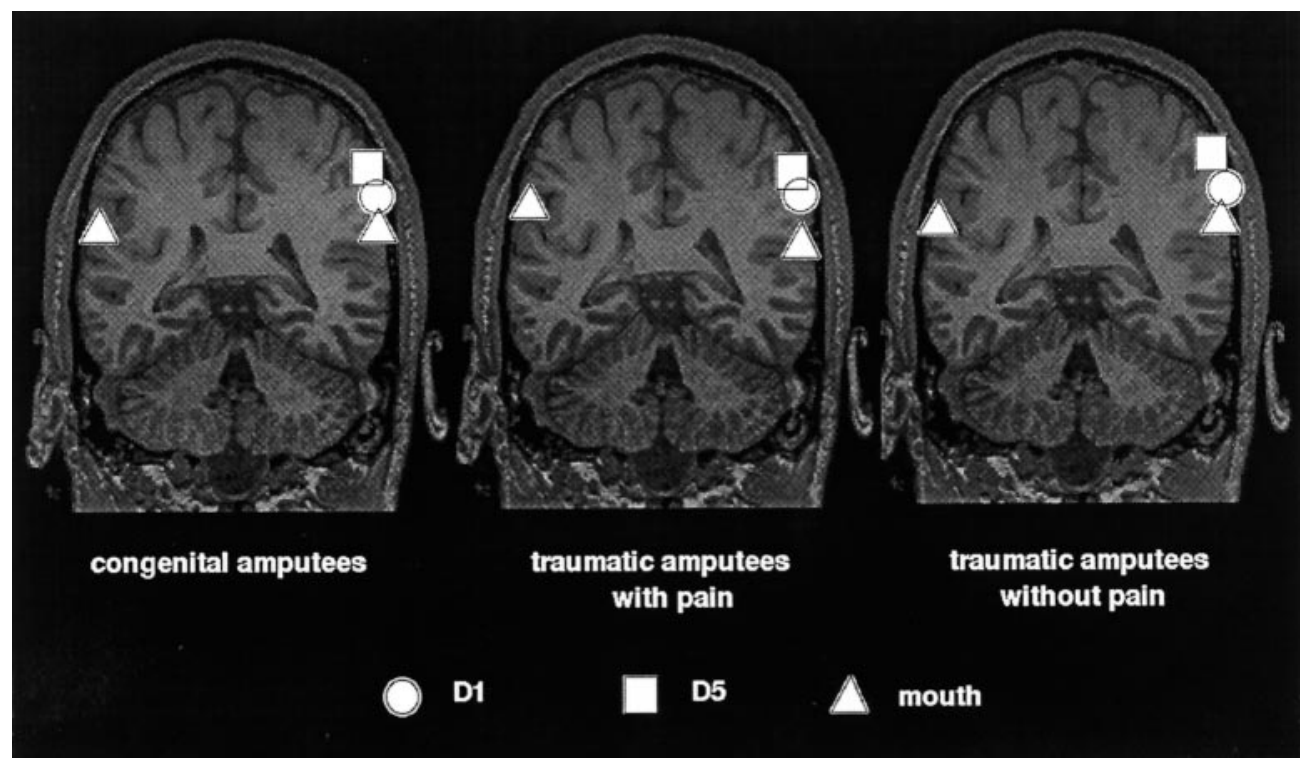

Fig. 1 Locations of the representation of the first (D1, circle) and fifth (D5, square) digits and both sides of the the mouth (triangles) in the three groups of patients superimposed on a coronal section of a magnetic resonance (MR) image of a healthy control. The cortical representation of the amputated side is depicted on the left side (right hemisphere) of each MR image; the cortical representation of the intact side is shown on the right side (left hemisphere). The dipole locations of the digits and the mouth, which can be located in the depths of sulci or within cortex on the MR image, were projected onto the cortical surface based on the algorithm described by Dale and Sereno (1993). It involves modeling the surface of a twodimensional projection of the coronal section of the cortex as a onedimensional line; a deep dipole location is projected onto this line at the point that is closest to the dipole (i.e., a line from the dipole perpendicular to the closest representation of the cortical surface). Note that the cortical representation of the mouth on the amputation side has shifted toward the hand region in the traumatic amputees with phantom limb pain but not in the congenital amputees or amputees without phantom limb pain

crimination was assessed using a caliper-probe opened to progressively larger extensions, starting at $1 \mathrm{~mm}$ in three ascending series. A Medoc thermal stimulator was used to determine thermal thresholds, which were measured using three ascending series. Electric stimulation thresholds were also assessed in three ascending series using a Tönnies electric stimulator, which delivered unipolar impulses of $100 \mathrm{~ms}$ duration. The stimuli were applied to the thenar eminence of the intact hand (both hands in the healthy controls), $6 \mathrm{~cm}$ proximal to the amputation line on the amputated arm, a homologous site on the intact arm, and both corners of the mouth. Phantom limb and stump pain were assessed by three methods: (a) the pain intensity scale of the West Haven-Yale Multidimensional Pain Inventory (MPI; Kerns et al. 1985; Flor et al. 1990), a reliable and valid measure of the amount of pain experienced, which was administered separately for phantom and stump pain; (b) a phantom and stump phenomena interview, including the Pain Experience Scale (Schmerzempfindungsskala; Geissner 1997), which consists of 24 pain adjectives derived from the McGill pain questionnaire. These 24 descriptors were scored on a 4-point scale according to the extent to which they accurately described the subject's pain experience. The scale was administered separately for phantom limb pain, stump pain, and preamputation pain. (c) A 10-cm visual analog scale with the endpoints "no pain" and "unbearable pain." Nonpainful phantom phenomena (e.g., telescoping) and nonpainful stump sensations (e.g., itch, pressure) were measured in the phantom and stump phenomena interview (Flor et al. 1995).
Assessment of cortical reorganization

Cortical reorganization was determined by neuromagnetic source imaging. In all subjects (except for one congenital amputee for whom only subjective data could be obtained), at least the following four sites were stimulated by using light superficial pressure applied via a pneumatic stimulator: (1) the first and (2) fifth digits of the (intact) hand, the lower lip near the (3) left and (4) right corners of the mouth. In two congenital amputees, the first toe was stimulated bilaterally in order to determine the full extent of the reorganization along the sensory homunculus. Using a BTi neuromagnetometer, magnetic fields were recorded from 37 locations over a circular concave area $(14.4 \mathrm{~cm}$ diameter) above the parietotemporal cortex contralateral to the site of the stimulation. Recordings were carried out in a magnetically shielded room. Subjects lay in a lateral position with their whole body supported by vacuum cushions. At each stimulation site, 1000 stimuli were delivered at an average rate of $0.5 \mathrm{~Hz}$ (interval between stimulus onsets, $500 \pm(50 \mathrm{~ms})$. The sequence of sites at which stimuli were presented was varied according to a fixed, irregular order across subjects. After each train of 1000 stimuli, the subjects indicated the primary and secondary (if any) location of the perceived stimulation as well as its quality and intensity. The magnetoencephalogram (MEG) was sampled at a rate of $520.5 \mathrm{~Hz}$. The evoked magnetic responses from each stimulation site were averaged (from -100 to $+250 \mathrm{~ms}$ ) and digitally filtered with a bandpass of $0.01-100 \mathrm{~Hz}$. In order to exclude artifacts, a response was omitted from the mean if its range exceeded $2 \mathrm{pT}$ in any of the MEG channels. For each magnetic field distribution, a single equivalent current dipole (ECD) model (best-fitting local sphere) was fitted within the latency range from 20 to $70 \mathrm{~ms}$. From the points with a goodness of fit larger then 0.95 and a confidence volume smaller then $300 \mathrm{~mm}^{3}$, the region with the maximal field power (measured as root-mean-square across channels) was selected. To illustrate the measure of reorganization used, these ECD locations were mapped onto the cortical surface, which was reconstructed from a magnetic resonance image using the procedure described by Lütkenhöner et al. (1995). The mirror images of digits 1 and 5 were obtained by projecting the centers of magnetic activity on the intact side across the midsagittal plane onto the hemisphere contralateral to the amputation side. To obtain an estimate of the extent of the reorganization that had occurred, a comparison was made of the distances in the coronal projection. The mean difference in the two distance measures (i.e., mean coronal shift in the dipole of the amputation side face area relative to the mean of the fingers) was used as the measure of cortical reorganization (Flor et al. 1995). 
Table 2 Thermal and electrical perception threshold, pain threshold, and pain tolerance levels for congenital amputees and a healthy control group

\begin{tabular}{|c|c|c|c|c|c|c|c|c|c|c|c|}
\hline \multicolumn{6}{|c|}{ Congenital amputees $(n=5)$} & \multicolumn{6}{|c|}{ Healthy controls $(n=10)$} \\
\hline \multicolumn{12}{|c|}{ Perception threshold $\left({ }^{\circ} \mathrm{C}\right)$} \\
\hline Mean & 33.48 & 32.96 & 33.51 & 32.75 & 32.74 & 34.15 & 33.87 & 34.68 & 35.20 & 33.14 & 33.13 \\
\hline $\mathrm{SD}$ & 0.33 & 0.27 & 0.59 & 0.42 & 0.35 & 2.45 & 1.80 & 1.01 & 0.64 & 1.24 & 0.95 \\
\hline \multicolumn{12}{|c|}{ Pain threshold $\left({ }^{\circ} \mathrm{C}\right)$} \\
\hline Mean & 41.84 & 39.53 & 38.63 & 39.17 & 38.33 & 40.12 & 41.15 & 40.90 & 42.02 & 37.11 & 37.30 \\
\hline SD & 5.32 & 3.62 & 3.28 & 3.77 & 3.59 & 3.73 & 3.90 & 4.64 & 3.36 & 3.06 & 2.74 \\
\hline \multicolumn{12}{|c|}{ Pain tolerance $\left({ }^{\circ} \mathrm{C}\right)$} \\
\hline Mean & 47.70 & 43.75 & 43.00 & 42.43 & 41.83 & 45.59 & 45.73 & 46.70 & 48.12 & 42.54 & 42.54 \\
\hline SD & 3.82 & 3.26 & 3.81 & 2.71 & 3.64 & 3.10 & 3.79 & 2.92 & 1.97 & 3.98 & 3.98 \\
\hline \multicolumn{12}{|c|}{ Electrical Stimulation } \\
\hline SD & 1.48 & 2.61 & 1.68 & 1.28 & 1.99 & 1.81 & 1.78 & 0.79 & 0.87 & 0.63 & 0.55 \\
\hline \multicolumn{12}{|c|}{ Pain threshold (mA) } \\
\hline Mean & 9.53 & 9.71 & 7.21 & 9.13 & 9.46 & 10.78 & 10.85 & 11.60 & 11.60 & 7.59 & 7.97 \\
\hline $\mathrm{SD}$ & 8.50 & 8.48 & 5.70 & 8.24 & 8.14 & 3.63 & 4.26 & 2.07 & 1.82 & 2.34 & 2.63 \\
\hline \multicolumn{12}{|c|}{ Pain tolerance $(\mathrm{mA})$} \\
\hline Mean & 11.85 & 11.98 & 10.79 & 10.81 & 10.78 & 15.46 & 14.86 & 17.22 & 17.82 & 12.91 & 12.67 \\
\hline SD & 8.25 & 8.42 & 7.81 & 7.30 & 7.42 & 4.20 & 5.18 & 3.29 & 3.51 & 4.90 & 5.15 \\
\hline
\end{tabular}

\section{Results}

\section{Cortical reorganization}

The most extensive reorganization was observed in the traumatic amputees with phantom limb pain $(M=2.22 \mathrm{~cm}$, SD 0.78), whereas the congenital amputees $(M=0.69 \mathrm{~cm}$, SD 0.24$)$ and the traumatic amputees without phantom limb pain displayed almost no reorganization $(M=$ $0.27 \mathrm{~cm}, \mathrm{SD} 0.25)$. These group differences were significant $\left(F_{2,10}=20.10, P<0.001\right.$; see Fig. 1$)$. Individual post hoc tests revealed significant differences between the pain-free amputees and the amputees with phantom pain $(P<0.001)$ and the congenital amputees and the amputees with phantom limb pain $(P<0.01)$, but not between the congenital and pain-free amputees. In the two congenital amputees where the location of the toe was assessed, the dipole of the cortical representation of the toe on the amputation side was very similar to that of the intact side (euclidean distance: $M=0.71 \mathrm{~cm}, \mathrm{SD} 0.32$ ). Phantom limb pain was significantly positively correlated with cortical reorganization $(r=0.87, N=13, P<0.001)$, but not with nonpainful phantom sensations $(r=0.34, N=13$, n.s. $)$ or any other amputation-related variables such as time since amputation or stump length.

\section{Perceptual phenomena}

None of the congenital amputees had any painful or nonpainful phantom phenomena, although three of the congenital amputees had experienced trauma to the stump (surgery, painful inflammation, stump pain). Stump pain was significantly more severe in the traumatic amputees with phantom limb pain than in the congenital group, but not significantly different in the two traumatic groups $\left(F_{2,11}=4.66, P<0.05 ; t\right.$-test, $P<0.05$; see Table 1$)$. Phantom sensations and painful stump sensations were only present in the two traumatic amputee groups, with no significant differences between them. Mislocalization of sensation to the missing limb was nonexistent in the congenital amputees, but present in one of five traumatic amputees without phantom limb pain and three of four traumatic amputees with phantom limb pain (overall $\chi^{2}(2)=7.25$, $P<0.05)$.

When the number of points that elicited mislocalization were compared, the congenital amputees reported none, the traumatic amputees without pain 0.40 , and the traumatic amputees with pain 5.75 on the average (Kruskal-Wallis $=6.87, P<0.05$ ). Telescoping was not reported by any of the congenital amputees, but was present in all four traumatic amputees with pain and in two of five traumatic amputees without pain. Two-point discrimination at the stump was not significantly better in any of the amputee groups than at the homologous site on the intact arm (see Table 1). Thermal and electrical perception, pain thresholds, and pain tolerance values are presented in 
Table 2 . These data were only available for the congenital amputees and for the ten healthy controls. Contrary to the literature (Weinstein et al. 1964), the congenital amputees did not show significant differences in perception on the stump as compared to the intact arm or any other abnormal sensitivity as compared to the healthy control group, and they were not more sensitive at the stump as compared to the contralateral arm.

\section{Discussion}

Phantom phenomena in congenital amputees

The data of this study confirm the assumption that nonpainful phantom sensations and phantom pain are rare and quite possibly nonexistent in congenital amputees. None of our adult congenital subjects showed any phantom phenomena or mislocalization of sensation. If one accepts that the base rate for nonpainful phantom phenomena may range between 7 and 18\% (Weinstein et al. 1964; Saadah and Melzack 1994), it is possible that our sample was too small to detect any phantom phenomena. It must, however, also be noted that all our subjects were adults as compared to the Weinstein et al. (Weinstein and Sersen 1961; Weinstein et al. 1964) studies and may have been better able to differentiate true from imagined phantom limbs, as pointed out by Burchard (1965). Pending larger sample sizes, the question regarding the frequency of the occurrence of phantom limbs in congenital aplasias remains open.

The fact that three of our five congenital amputees had sustained trauma to the stump although none of them developed a phantom phenomenon brings into question the belief of Saadah and Melzack (1994) that intense input might have been the cause for the late-developing phantom limbs in their congenital amputees. Saadah and Melzack failed to ascertain the base rate of the occurrence of trauma to the residual portion of a limb in the congenital amputees without phantom phenomena. It may be quite high (Minnes and Stack 1990), and we therefore do not know the number of congenital amputee respondents to Saddah and Melzack's mail questionnaire who received substantial trauma to the residual limb and who, as in our sample, did not experience a late emergence of phantom limb sensation. Since the Saddah and Melzack data apparently do not represent a general phenomenon, there is question as to the extent to which they support Melzack's (1990) formulation of a genetically determined neuromatrix underlying phantom phenomena.

\section{Cortical reorganization and sensory perception} in congenital amputees

In accordance with the absence of phantom limb pain and phantom phenomena, cortical reorganization in the congenital amputees was low and not significantly different from that of traumatic amputees without phantom limb pain. In contrast, traumatic amputees with phantom limb pain showed substantial cortical reorganization, as has been previously reported (Flor et al. 1995; Birbaumer et al. 1997). Cortical reorganization showed a significant positive correlation here with phantom limb pain but not with nonpainful phantom phenomena. In line with this lack of cortical reorganization, the congenital amputees also showed normal perceptual ability at the amputation stump (Merzenich et al. 1984). It was, however, surprising that the traumatic amputees did not have more sensitive stumps as previously reported (Teuber et al. 1949). One factor involved might be that our sensitivity assessment was limited to a point about $6 \mathrm{~cm}$ proximal to the stump; this might have been too far removed from the amputation site. In addition, the clinical samples used in previous research might be very different from our self-selected amputee sample. Our data indicate that the loss of input from a limb in the pre- or early postnatal stage does not lead to significant reorganizational changes in SI (as one might deduce from animal studies; see Merzenich et al. 1984; Pons et al. 1991; Florence and Kaas 1995)].

The congenital amputees in this study also did not develop phantom limb pain. The factors that are related to the development of phantom limb pain await further clarification. It is possible that traumatic amputation leads in some cases to a preponderance of nociceptive inputs, as has been observed after dorsal rhizotomy (Rausell et al. 1992), and that this enhanced nociceptive input provides the stimulation needed for phantom limb pain to develop. Spitzer et al. (1995) have suggested that noisy inputs (e.g., from stump neuroma) may lead to reorganizational changes; an interpretation consistent with their neural network model of sensory map formation. Nyström and Hagbarth (1981) provided evidence from microelectrode recordings that such spontaneous discharges are present in patients with phantom limb pain, although they failed to include control amputees without phantom limb pain in this study. Peripheral input might be important in some, but not all, cases of phantom limb pain (Birbaumer et al. 1997). An additional factor might be some type of cortical somatosensory pain memory, whose subjective features have been described by Katz and Melzack (1990).

We have recently reported indicators of massive reorganization of SI in chronic back pain with a high positive correlation between the magnitude of the reorganization and the chronicity of the pain problem (Flor et al. 1997). An expansion of primary cortical areas coding for pain (see Kenshalo and Douglass 1995 for a review of the role of SI in pain perception) either due to a chronic or acute pain condition prior to the amputation or related to peri- and postamputation pain might create permanent memories for pain that are activated subsequent to an amputation. The larger the prior expansion, the larger the subsequent reorganizational changes might be.

Although we have thus far addressed only the functional reorganization in SI after amputation, it is quite possible that the original locus of these alterations is not in somatosensory cortex but is rather at the level of the 
spinal cord or the thalamus (Howe 1983; Florence and Kaas 1995; Jain et al. 1997). Furthermore, the role of interhemispheric transfer requires investigation. Whereas nonpainful stimulation of the hand results primarily in activation of the contralateral cortex, pain is processed bilaterally. It remains to be investigated which stimulation might activate representational zones ipsilateral to the intact hand in subjects where we fail to detect distortions of homuncular organization when the amputated hand is stimulated.

Dissociation of cortical areas involved in perception of nonpainful phantom sensation and phantom limb pain

The motor activation study by Kew et al. (1994) suggested that both S1/M1 and area 5 in posterior parietal cortex might play an important role in the experience of phantom limbs. The enhanced excitability of M1 is in accordance with previous work by Cohen et al. (1991) that used transcranial magnetic stimulation. However, these studies did not examine the relation of cortical activation and the experience of phantom limb pain or other phantom phenomena. In a study using transcranial magnetic stimulation, we were able to show that increased output from M1 is present in amputees with phantom limb pain (Flor et al. 1996), and that it is uncorrelated with the presence of nonpainful phantom limb phenomena. Aside from the study by Kew at al. (1994), there have been no reports concerning the role of area 5 following limb amputations. Area 5 (and also area 7) plays an important role in the maintenance of an image of one's own body and limb position (Stein 1989). Moreover, Dong et al. (1996) have suggested that it might also have important functions in the processing of painful stimuli. There is some anecdotal evidence that damage to this area or other portions of the postcentral gyrus by cerebrovascular insults or surgery results in the disappearance of the perception of phantom limb and/or phantom pain (Pool and Bridges 1953; Appenzeller and Bicknell 1969; Weinstein et al. 1969). We did not study activity in area 5 in this experiment. However, we would like to suggest that an anatomical dissociation might be present: whereas phantom limb pain might be linked to reorganizational changes in SI/MI (and potentially SII), the perception of a phantom limb, nonpainful limb sensation, and other phantom phenomena (e.g., mislocalization, telescoping) might be closely tied to activation of area 5 in posterior parietal cortex. Further examination of changes in these cortical areas related to phantom phenomena might assist in the elucidation of the causes of phantom limb pain and nonpainful phantom limbs.

Acknowledgment This work was supported by the Deutsche Forschungsgemeinschaft.

\section{References}

Appenzeller O, Bicknell JM (1969) Effects of nervous system lesions on phantom experience in amputees. Neurology 19:141-146

Birbaumer N, Lutzenberger W, Montoya P, Larbig W, Unertl K, Töpfner S, Grodd W, Taub E, Flor H (1997) Effects of regional anesthesia on phantom limb pain are mirrored in changes in cortical reorganization. J Neurosci 17:5503-5508

Boeri R, Negri S (1954) I fenomeni sensitivi d'amputazione nell'èta infanto-giovanile. Riv Sper Freniatr Med Leg Alien Ment 78: $721-733$

Burchard JM (1965) Zur Frage der Natur von Phantomerlebnissen bei angeborener Gliedmaßenverstümmelung. Arch Psychiatr Z Neurol 207:360-377

Cohen LG, Bandinelli F, Findley TW, Hallet, M (1991) Motor reorganization after upper limb amputation in man. Brain 114:615-627

Dale AM, Sereno MI (1993) Improved localization of cortical activity by combining EEG and MEG with MRI cortical surface reconstructions: a linear approach. J Cogn Neurosci 5:162-176

Dong WK, Hayashi T, Roberts VJ, Fusco BM, Chudler EH (1996) Behavioral outcome of posterior parietal cortex injury in the monkey. Pain 64:579-587

Flor H, Rudy TE, Birbaumer N, Streit B, Schugens MM (1990) Zur Anwendbarkeit des West Haven-Yale Multi-dimensional Pain Inventory im deutschen Sprachraum: Daten zur Reliabilität und Validität des MPI-D. Schmerz 4:82-87

Flor H, Elbert T, Knecht S, Pantev C, Birbaumer N, Larbig W, Taub E (1995) Phantom limb pain as a perceptual correlate of massive cortical reorganization in upper limb amputees. Nature 375: $482-484$

Flor H, Birbaumer N, Karl A, Grüsser S, Mühlnickel W, Lutzenberger W (1996) Reorganization of motor and somatosensory cortex is related to phantom limb pain but not to nonpainful phantom phenomena. Psychophysiology 33:63

Flor H, Braun C, Elbert T, Birbaumer N (1997) Extensive reorganization of primary somatosensory cortex in chronic back pain patients. Neurosci Lett 244:5-8

Florence SL, Kaas JH (1995) Large-scale reorganization at multiple levels of the somatosensory pathway follows therapeutic amputation of the hand in monkeys. J Neurosci 15:8083-8095

Geissner E (1997) Die Schmerzempfindungsskala. PVU, Weinheim

Hall EJ, Flament D, Fraser C, Lemon RN (1990) Non-invasive brain stimulation reveals reorganised cortical outputs in amputees. Neurosci Lett 116:379-386

Herrmann J, Opitz JM (1977) The SC phocomelia and the Roberts syndrome: nosologic aspects. Eur J Pediatr 125:117-134

Holmes LB, Borden IVS (1974) Phocomelia, flexion deformities and absent thumbs: a new hereditary upper limb malformation. Pediatrics 54:461-465

Howe JF (1983) Phantom limb pain - a re-afferentation syndrome. Pain 15:101-107

Jain N, Catania KC, Kaas JH (1997) Deactivation and reactivation of somatosensory cortex after dorsal spinal cord injury. Nature 386:495-498

Jensen TS, Krebs B, Nielsen J, Rasmussen P (1983) Phantom limbs, phantom pain and stump pain in amputees during the first 6 months following limb amputation. Pain 17:243-256

Jørring K (1971) Amputation in children. Acta Orthop Scand 42:178-186

Katz J, Melzack R (1990) Pain "memories" in phantom limbs: review and clinical observations. Pain 43:319-336

Kenshalo DR, Douglass DK (1995) The role of the cerebral cortex in the experience of pain. In: Bromm B, Desmedt J (eds) Pain and the brain: from nociception to cognition, Elsevier, Amsterdam, pp 21-34

Kerns RD, Turk DC, Rudy TE (1985) The West Haven-Yale Multidimensional Pain Inventory (WHYMPI). Pain 23:345-356

Kew JJ, Ridding MC, Rothwell JC, Passingham RE, Leigh PN, Sooriakumaran S, Frackowiak RS, Brooks DJ (1994) Reorganization of cortical blood flow and transcranial magnetic stimulation maps in human subjects after upper limb amputation. J Neurophysiol 72:2517-2524 
Knecht S, Henningsen H, Elbert T, Flor H, Höhling C, Pantev C, Taub E (1996) Reorganizational and perceptual changes after amputation. Brain 119:1213-1219

Kolb LC (1954) The painful phantom: psychology, physiology and treatment. Thomas, Springfield, IL

Krane EJ, Heller LB (1995) The prevalence of phantom sensation and pain in pediatric amputees. J Pain Symptom Manage 10:21-29

Lütkenhöner B, Menninghaus E, Steinsträter $\mathrm{O}$, Wienbruch $\mathrm{C}$, Gißler M, Elbert T (1995) Neuromagnetic source analysis using magnetic resonance images for the construction of source and volume conductor model. Brain Topogr 7:291-299

Melzack RA (1990) Phantom limbs and the concept of a neuromatrix. Trends Neurosci 13:88-92

Merzenich MM, Nelson RJ, Stryker MP, Cynader MS, Shoppmann A, Zook JM (1984) Somatosensory cortical map changes following digit amputation in adult monkeys. J Comp Neurol 224:591605

Minnes PM, Stack DM (1990) Research and practice with congenital amputees:making the whole greater than the sum of its parts. Int J Rehab Res 13:151-160

Nyström B, Hagbarth K-E (1981) Microelectrode recordings from transsected nerves in amputees with phantom limb pain. Neurosci Lett 27:211-216

Pfeiffer RA, Santelman R (1977) Limb anomalies in chromosomal aberrations. Birth Defects 8:319-337

Pick A (1915) Zur Pathologie des Bewußtseins vom eigenen Körper. Neurol Centralbl 34:257-265

Poeck K (1964) Phantoms following amputation in early childhood and in congenital absence of limbs. Cortex 1:269-275

Pons TP, Garraghty PE, Ommaya AK, Kaas JH, Taub E, Mishkin M (1991) Massive cortical reorganization after sensory deafferentation in adult macaques. Science 252:1857-1860

Pool JL, Bridges TJ (1953) Subcortical parietal lobotomy for relief of upper extremity phantom limb syndrome. J Nerv Ment Dis 118:469-470

Ramachandran VS, Rogers-Ramachandran D, Stewart M (1992) Perceptual correlates of massive cortical reorganization. Science 258:1159-1160
Rausell E, Cusick CG, Taub E, Jones EG (1992) Chronic deafferentation in monkeys differentially affects nociceptive and nonnociceptive pathways distinguished by specific calcium-binding proteins and down-regulates $\gamma$-aminobutyric acid type A receptors at thalamic levels. Proc Natl Acad Sci USA 89:25712575

Riese W, Bruck G (1950). Le membre phântome chez l'enfant. Rev Neurol 83:221-222

Saadah ES, Melzack R (1994) Phantom limb experiences in congenital limb-deficient adults. Cortex 30:479-485

Sherman RA (1997) Phantom pain. Plenum Press, New York

Sherman RA, Sherman CJ, Parker L (1984) Chronic pain and stump pain among American veterans: results of a survey. Pain 18:8395

Simmel M (1956) On phantom limbs. Arch Neurol Psychiatry 75:637-647

Simmel M (1961) The absence of phantoms for congenitally missing limbs. Am J Psychol 74:467-470

Skoyles JR (1990) Is there a genetic component to body schema? Trends Neurosci 13:409

Sohn DL (1914) The psychic complex in congenital deformity. NY Med J 100:959-961

Spitzer M, Böhler P, Weisbrod M, Kischka U (1995) A neural network model of phantom limbs. Biol Cybern 72:197-206

Stein JF (1989) Representation of egocentric space in the posterior parietal cortex. Q J Exp Physiol 74:583-606

Teuber HL, Krieger HP, Bender MB (1949) Reorganization of sensory function in amputation stumps; two-point discrimination. Fed Proc 8:156

Vetter RJ, Weinstein S (1967) The history of the phantom in congenitally absent limbs. Neuropsychologia 5:335-338

Weinstein S, Sersen EA (1961) Phantoms in cases of congenital absence of limbs. Neurology 10:905-911

Weinstein S, Sersen EA, Vetter RJ (1964) Phantoms and somatic sensation in cases of congenital aplasia. Cortex 1:276-290

Weinstein S, Vetter RJ, Shapiro G, Sersen EA (1969) The effects of brain damage on the phantom limb. Cortex 5:91-103 